\title{
The role of solid feed amount and composition and of milk replacer supply in veal calf welfare
}

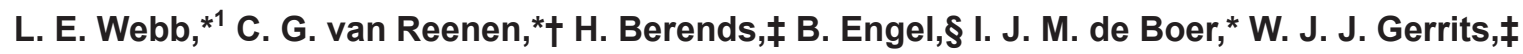 \\ and E. A. M. Bokkers* \\ *Animal Production Systems Group, PO Box 338, \\ †Livestock Research, Research Centre, PO Box 338, \\ $\ddagger$ Animal Nutrition Group, PO Box 338, and \\ §Biometris, PO Box 100, Wageningen University, 6700 AC Wageningen, the Netherlands
}

\section{ABSTRACT}

Diets used in veal production were linked with welfare problems: that is, behavioral and gastrointestinal health disorders. This study aimed to determine how indicators of calf welfare, that is, behavior and some characteristics of the feces reflecting gastrointestinal health status, are affected by (1) different amounts and compositions of solid feed (SF), (2) the addition of ad libitum long straw to a typical veal diet, and (3) milk replacer (MR) being fed via automated milk dispensers (AMD). Two-week-old Holstein-Friesian bull calves $(\mathrm{n}=270)$ were used in this study. In a $4 \times 2$ factorial design, 32 pens ( 5 calves per pen) were allocated to different levels of SF (SF1, SF2, SF3, or SF4) and roughage-to-concentrate ratios (20:80 or 50:50). The experimental period (13 to $29 \mathrm{wk}$ of age) was preceded by an adaptation period (3 to 12 wk of age). Targeted total dry matter (DM) intake from SF during the experimental period was $20 \mathrm{~kg}$ of DM for SF1, $100 \mathrm{~kg}$ of DM for SF2, $180 \mathrm{~kg}$ of DM for SF3, and $260 \mathrm{~kg}$ of DM for SF4. The roughage part of the SF was $50 \%$ maize silage and 50\% chopped wheat straw (on a DM basis). Ten additional pens were allocated to 2 treatments with ad libitum SF, with either (1) SF components in separate troughs (SEP) or (2) SF components mixed, with the composition being equal to the choice of SEP calves in the preceding week (MIX). Another 4 pens were fitted with racks filled with long wheat straw (STR) and fed SF2 with a roughage-to-concentrate ratio of 20:80. All the aforementioned pens received MR in buckets. Finally, 8 pens were allocated to 1 of 2 SF levels: SF1 or SF2 (with a roughage-to-concentrate ratio of 50:50) and fed MR via an AMD. Milk replacer provision was adjusted every 2 wk to achieve similar rates of carcass gain across treatments (excluding SEP, MIX, and STR). Behavior was recorded at 15 and 24 wk using

Received June 30, 2014.

Accepted February 15, 2015.

${ }^{1}$ Corresponding author: laura.webb@wur.nl instantaneous scan sampling. The prevalence of diarrhea and clay-like feces, which signal ruminal drinking, was monitored at 14 and 25 wk. More roughage, but not concentrate, increased rumination and decreased tongue playing. The STR calves had higher rumination and lower abnormal behavior levels compared with calves without ad libitum straw. Offering MR via an AMD reduced tongue playing at $15 \mathrm{wk}$. Tongue playing frequency was related to both roughage amount and AMD feeding, suggesting 2 separate motivations (i.e., rumination and sucking) underlying the development of this behavior. Only SF amount affected aspects of feces: SF1 calves had the highest diarrhea incidence. No effect of diet was found on clay-like feces.

Key words: behavior, roughage-to-concentrate ratio, milk feeding method, solid feed level, veal calf

\section{INTRODUCTION}

Diets commonly used in veal production have been linked with several welfare impairments, including behavioral and gastrointestinal health problems (Bokkers and Koene, 2001; Brscic et al., 2011). Veal calves develop abnormal oral behaviors such as excessive oral manipulation of the pen and abnormal rolling of the tongue, that is, tongue playing (Leruste et al., 2014), most likely due to an inadequate provision of solid feed (SF) and, in particular, insufficient structure in the SF (Mattiello et al., 2002; Webb et al., 2013; Leruste et al., 2014). It has been suggested that little structure limits natural rumination, which in turn leads to frustration and stress in the calves and ultimately to the development of abnormal oral behaviors (Mattiello et al., 2002; Webb et al., 2013; Webb, 2014). Increased rumination can occur through increasing the provision of SF (Webb et al., 2012, 2013), increasing the proportion of roughage or the presence of longer particles in the SF (Balch, 1971; Mertens, 1997; Kahyani et al., 2013), or providing coarser roughage sources (Mattiello et al., 2002; Webb et al., 2013). However, most studies ignore potential differences in satiety, by providing 
equal amounts of milk replacer (MR) to calves, while the amounts of SF differ. It may be more valuable to maintain equal growth between different feeding treatments by adjusting MR provision. In addition, increasing the SF provision of veal calves usually involves an increase in concentrate provision, rather than roughage provision, to maximize growth efficiency (Berends et al., 2014). It is, thus, important to understand how increased concentrate provision, as opposed to roughage, may affect behavior and gastrointestinal health.

Certain authors have even suggested that allowing calves to select their own diet, from a sound choice of components, is the best, or only way, to meet individual nutritional, physiological, and behavioral requirements (Manteca et al., 2008). Therefore, the behavior of calves offered novel diets aimed at improving welfare should be directly compared with the behavior of calves with ad libitum access to SF components.

Other than rumination, natural sucking is another natural behavior that may be thwarted in veal systems, because of the feeding of MR via open buckets or troughs without teats (Brscic et al., 2011). This restriction may result in nonnutritive sucking of pen mates, observed in dairy calves (de Passillé and Rushen, 1997). Limited MR feeding, albeit via teats, has also been associated with tongue playing and cross-sucking in dairy calves (Froberg and Lidfors, 2009). A careful comparison between effects of SF provision versus MR feeding method on the behavior and gastrointestinal health of veal calves is required.

The aim of this study was to determine how indicators of calf welfare, here mainly behavior and some characteristics of the feces reflecting gastrointestinal health status, may be affected by (1) different amounts and compositions of SF, (2) the addition of ad libitum long straw to a typical veal diet, and (3) MR being fed via buckets or automated milk dispensers (AMD).

\section{MATERIALS AND METHODS}

All procedures complied with the Dutch law for animal experiments, which itself complies with the ETS123 (Council of Europe 1985 and the 86/609/EEC Directive). Procedures were further sanctioned by Wageningen University's Committee on Animal Care and Use. The study ran from July to December 2012. General performance, postmortem gastrointestinal health, and meat-quality characteristics for the $4 \times 2$ design are described in a separate article (Berends et al., 2014).

\section{Animals, Experimental Design, and Housing}

Two-week-old Holstein-Friesian bull calves $(\mathrm{n}=270$; $45.1 \pm 0.2 \mathrm{~kg}$ ) were purchased from a Dutch dairy-calf trader and transported to the experimental facilities, Scherpenzeel, the Netherlands. The calves were selected for similar weights and good clinical health and randomly allocated to pens, with 5 calves per pen. The pens were allocated to different feeding treatments (see next section), with the location of pens with different diet treatments within the barn being randomized. This means that pens with the same diet treatment were spread out across the barn, as much as possible. Certain practical limitations were associated with pens with ad libitum SF, with ad libitum straw, and with AMD. Pens with ad libitum SF were all located in the same location in the barn because of special feeding requirements, but some pens were close to a window, whereas others were located in the center of the barn. Pens with ad libitum straw provided in racks needed to be located against a barn wall for the fixation of the rack, but these pens were located at opposite sides of the barn. Pens with AMD needed to be near the central isle, but these pens were spread out across this isle as much as possible. These limitations regarding the randomized location of pens are not thought to have affected the results in any manner. All calves received MR and SF throughout the study (see Table 1 for nutrient composition). The SF consisted of concentrate and roughage (50\% maize silage and $50 \%$ chopped wheat straw on a DM basis). During the first 4 wk, calves were individually housed in $0.9-\mathrm{m}^{2}$ temporary pens inside the group pens (contact possible between calves from adjacent pens), to facilitate the monitoring of feeding behavior and health. Thereafter, calves were group housed in $9-\mathrm{m}^{2}$ pens with open fences, woodenslatted floors, and no bedding material. The study included 2 consecutive periods: an adaptation period (3 to 12 wk of age) and an experimental period (13 to 29 wk of age). Average temperature and relative humidity were $20.0 \pm 0.3^{\circ} \mathrm{C}$ and $85.5 \pm 0.7 \%$ during the adaptation period and $12.6 \pm 0.6^{\circ} \mathrm{C}$ and $91.7 \pm 0.6 \%$ during the experimental period. The barn was lit by natural light and by artificial lighting between 0500 and 2300 h. Health was monitored daily. Within the first $2 \mathrm{wk}$, calves were treated at the group level with antibiotics because of disease and based on veterinarian advice: colistin and oxytetracycline (diarrhea), doxycycline (lung infections), and tilmicosin (bovine respiratory disorder). Thereafter, calves were treated when needed according to a veterinarian protocol. Sick calves were individually housed within the group pen to facilitate the monitoring of feeding behavior and health. Sick calves that showed indications of ruminal drinking (pasty, light-colored feces suggesting large amounts of MR were entering the rumen) were offered a floating teat during MR feeding. Hemoglobin levels were monitored 6 times during the experiment (at 5, 9, 13, 17, 21, 
Table 1. Nutrient composition $(\mathrm{g} / \mathrm{kg}$ of $\mathrm{DM})$ of solid feed ration components and milk replacer used during the experimental period

\begin{tabular}{lcccc}
\hline Nutrient & Concentrate $^{1}$ & $\begin{array}{c}\text { Maize } \\
\text { silage }\end{array}$ & $\begin{array}{c}\text { Wheat } \\
\text { straw }\end{array}$ & $\begin{array}{c}\text { Milk } \\
\text { replacer }\end{array}$ \\
\hline DM (g/kg of product) & 898 & 297 & 931 & 970 \\
CP $^{2}$ & 137 & 69 & 31 & 210 \\
Crude fat & 67 & 29 & 9 & 212 \\
Starch & 429 & 312 & 11 & 22 \\
NDF & 127 & 421 & 794 & - \\
\hline
\end{tabular}

${ }^{1}$ Concentrate composition: $36.2 \%$ corn, $20.6 \%$ lupins, $20.3 \%$ barley, $12.5 \%$ carob meal, $4.4 \%$ corn gluten meal, and $6 \%$ premix. Composition was designed to meet beef cattle requirements for minerals and vitamins (NRC, $2000)$.

${ }^{2} \mathrm{~N} \times 6.25$.

and 25 wk of age). Calves were injected with extra iron to comply with the minimum EU level of $4.5 \mathrm{mmol} / \mathrm{L}$ at the end of the fattening period. Calves were weighed every 2 wk. Water was offered for 20 min around noon in open buckets in the first $4 \mathrm{wk}$ and thereafter provided ad libitum via drinking nipples.

\section{Diets and Feeding}

This study comprised 3 separate experiments. Certain pens were used in 2 of these experiments to minimize the number of animals used. The experimental design is illustrated in Figure 1.

SF Level and Composition. In a $4 \times 2$ factorial design, 32 pens were allocated to different cumulative levels of SF (SF1, SF2, SF3, or SF4) and to 1 of 2 roughage-to-concentrate (R:C) ratios $(20: 80$ or $50: 50)$. Targeted total DMI from SF during the experimental period was $20 \mathrm{~kg}$ of DM for SF1, $100 \mathrm{~kg}$ of DM for SF2, $180 \mathrm{~kg}$ of DM for SF3, and $260 \mathrm{~kg}$ of DM for SF4. Milk replacer was fed in open buckets. Intakes of these calves at 15 and 24 wk of age are shown in Table 2. Two ad libitum SF treatments were included for comparison with pens from the $4 \times 2$ design, with either SF components in 3 separate troughs enabling calves to select their own composition (SEP) or SF components mixed together (MIX). Intake of SEP pens was recorded daily, and the proportions of concentrate, maize silage, and straw were calculated and averaged across all pens per week. From these averages, the mixture for MIX pens was prepared and fed ad libitum the following week.

Ad Libitum Provision of Straw. The effect of providing enrichment and increasing chewing and rumination opportunity was assessed by equipping 4 pens with a rack filled with long wheat straw (STR). The STR calves received the diet that was considered closest to what was done on Dutch commercial veal farms at the time of the experiment, that is, SF2 with R:C $20: 80$. These calves were compared with calves from the $4 \times 2$ factorial design that received the same diet but no straw rack (Figure 1). The number of straw bales provided to STR calves during the experiment was recorded.

SF Level and MR Feeding Method. In a $2 \times 2$ factorial design, 16 pens ( 8 of which were also included in the $4 \times 2$ design) were assigned to 1 of $2 \mathrm{SF}$ levels (SF1 or SF3 with R:C 50:50) and 1 of 2 MR feeding methods (open bucket or AMD).

General. Each treatment comprised 4 pens, except ad libitum SF groups. Ad libitum SF groups comprised

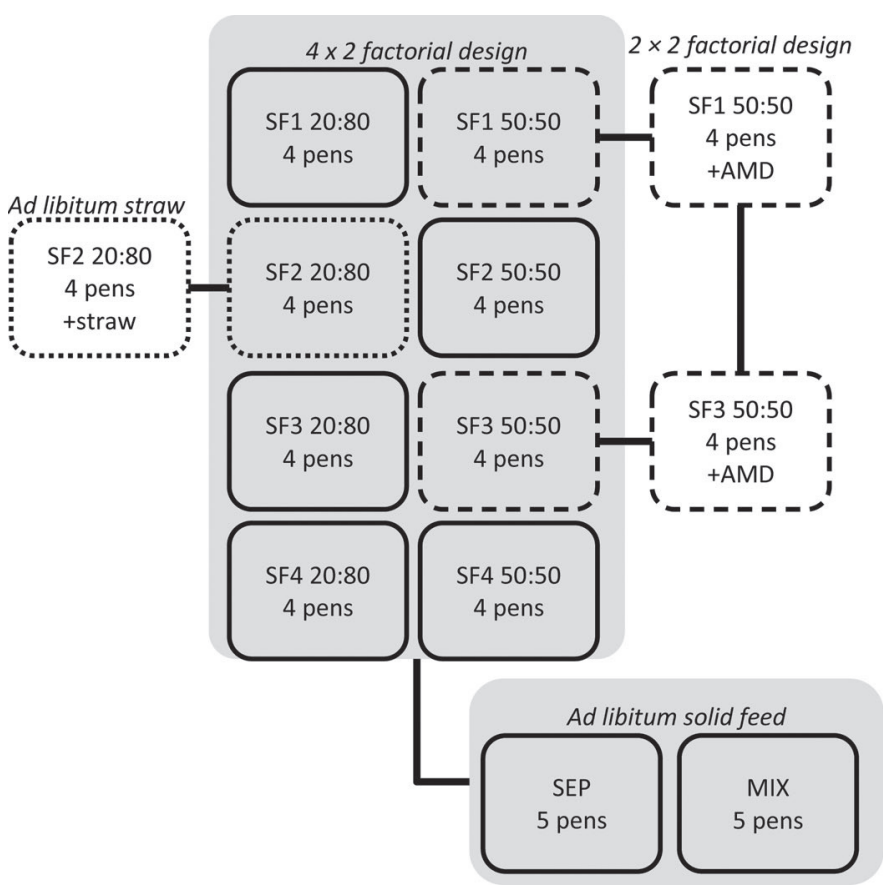

Figure 1. Illustration of experimental design. The design comprised 3 separate analyses: (1) $4 \times 2$ factorial design and ad libitum solid-feed (SF) treatments (gray), (2) presence or absence of ad libitum long straw in a rack (dotted lines), (3) $2 \times 2$ factorial design (dashed lines). SF1 to SF4 represent target DMI from 13 to 29 wk of age (20, $100,180,260 \mathrm{~kg}$ of DM, respectively). The roughage-to-concentrate ratios were either 20:80 or 50:50. AMD = automated milk dispensers (all other pens were fed milk replacer in buckets); SEP $=\mathrm{SF}$ components in separate troughs; MIX = SF components mixed together. 
Table 2. Mean solid feed (SF) intake ( $\mathrm{g}$ of DM/d) \pm SEM of calves in the $4 \times 2$ factorial design [i.e., fed 1 of $4 \mathrm{SF}$ levels with 1 of 2 roughage-to-concentrate (R:C) ratios] at 15 and 24 wk of age ${ }^{1}$

\begin{tabular}{|c|c|c|c|c|c|}
\hline \multirow[b]{2}{*}{ SF level } & \multirow[b]{2}{*}{$\mathrm{DMI}^{2}$} & \multicolumn{2}{|c|}{ R:C 20:80 } & \multicolumn{2}{|c|}{ R:C 50:50 } \\
\hline & & $15 \mathrm{wk}$ & $24 \mathrm{wk}$ & $15 \mathrm{wk}$ & $24 \mathrm{wk}$ \\
\hline SF1 & 20 & $137 \pm 0$ & $190 \pm 0$ & $132 \pm 0$ & $181 \pm 0$ \\
\hline SF2 & 100 & $577 \pm 0$ & $910 \pm 0$ & $562 \pm 0$ & $880 \pm 0$ \\
\hline SF3 & 180 & $1,077 \pm 0$ & $1,674 \pm 0$ & $916 \pm 67$ & $1,501 \pm 69$ \\
\hline SF4 & 260 & $1,569 \pm 0$ & $2,409 \pm 0$ & $1,476 \pm 25$ & $2,321 \pm 0$ \\
\hline
\end{tabular}

5 pens, to account for the large individual variation anticipated between calves (Webb et al., 2014), and potentially between pens, regarding total intake and preferences. During the adaptation period, all calves received R:C 50:50 to optimize rumen development (Suárez et al., 2007; Berends et al., 2012). Ad libitum SF groups were allocated to SF3. During the first $4 \mathrm{wk}$, calves received alfalfa hay instead of maize silage in an attempt to stimulate SF intake. A commercial starter MR (32.2\% whey powder, $30.0 \%$ skim milk powder; 223 $\mathrm{g} / \mathrm{kg}$ of CP, $180 \mathrm{~g} / \mathrm{kg}$ of DM crude fat) was fed to calves during the adaptation period. Body weights, ADG, and MR allowance during the adaptation period are shown in Table 3.

During the experimental period, R:C ratio differences, ad libitum SF and straw treatments, and AMD were implemented. Milk replacer provision was adjusted every $2 \mathrm{wk}$ based on BW to achieve similar rates of carcass gain (taking presumed differences in dressing percentages into account) across treatments (Table 4). The BW of SEP, MIX, and STR calves was not included in the adjustment of MR provision. The SEP and MIX calves received the MR allowance of calves with SF3 with R:C 50:50 and were fed MR in buckets (Table 4). The STR calves received the MR allowance of calves with SF2 with R:C 20:80 and were fed MR in buckets (Table 4 ).

Bucket-fed calves were fed MR at 0600 and $1600 \mathrm{~h}$. During MR feeding calves were locked in the fence to prevent them from ingesting the MR of other calves.
The AMD-fed calves obtained a new MR allowance in three 7 -h periods in the day. During the first $3 \mathrm{~h}$ of the day, AMD were automatically cleaned and MR was unavailable. Milk replacer concentration gradually increased from 125 to $188 \mathrm{~g} / \mathrm{L}$. Milk replacer refusals were recorded daily. The SF was fed immediately after MR feeding in the morning. The amount of SF was increased weekly with equal preplanned increments. The SF refusals were recorded daily.

\section{Behavioral Measurements}

Direct Observations. Behavioral observations were carried out for $2 \mathrm{~d}$ at both 15 and 24 wk of age, using instantaneous scan sampling. The ethogram used is described in Table 5 . The pens were divided into 3 groups based on location in the barn, and each group was observed for 30 min every $2 \mathrm{~h}$ from 0630 to $2030 \mathrm{~h}$ (with 30-min lunch break at $1230 \mathrm{~h}$ ). Each calf within each pen within each group was scanned at a 6-min interval. Groups were observed in a random order, and this order varied each observation day. Observations were carried out using a hand-held computer (Psion Teklogix Workabout Pro G2, Teklogix International Inc., Mississauga, Canada) with The ObserverXT (version 10, Noldus Information Technology, Wageningen, the Netherlands). All observations were done by a single observer.

Indirect Observations. Pens equipped with a straw rack were further observed indirectly to assess

Table 3. Average BW $(\mathrm{kg})$, ADG $(\mathrm{kg} / \mathrm{d})$, and milk replacer $(\mathrm{MR}, \mathrm{g} / \mathrm{d})$ provision $( \pm \mathrm{SEM})$ for each solid-feed (SF) level during the adaptation period (3 to 12 wk of age)

\begin{tabular}{|c|c|c|c|c|c|c|}
\hline SF level & $\mathrm{DMI}^{1}$ & $\begin{array}{l}\text { No. of } \\
\text { pens }\end{array}$ & BW 2 wk & BW 12 wk & $\mathrm{ADG}$ & MR \\
\hline SF1 & 20 & 8 & $45 \pm 0.3$ & $99 \pm 0.7$ & 0.7 & $525 \pm 18.3$ \\
\hline SF2 & 100 & 8 & $45 \pm 0.4$ & $100 \pm 0.8$ & 0.8 & $468 \pm 16.8$ \\
\hline SF3 & 180 & 8 & $45 \pm 0.2$ & $101 \pm 0.7$ & 0.8 & $428 \pm 15.5$ \\
\hline SF4 & 260 & 8 & $45 \pm 0.4$ & $101 \pm 0.9$ & 0.8 & $393 \pm 14.0$ \\
\hline
\end{tabular}


Table 4. Average BW $(\mathrm{kg})$, ADG $(\mathrm{kg} / \mathrm{d})$, and milk replacer $(\mathrm{MR}, \mathrm{g} / \mathrm{d})$ provision $( \pm \mathrm{SEM})$ per treatment during the experimental period $(13$ to 29 wk of age)

\begin{tabular}{|c|c|c|c|c|c|c|c|}
\hline Treatment $^{2}$ & $\mathrm{DMI}^{3}$ & $\mathrm{R}: \mathrm{C}^{4}$ & No. of pens ${ }^{5}$ & BW $12 \mathrm{wk}$ & BW $26 \mathrm{wk}$ & $\mathrm{ADG}$ & MR \\
\hline SF2 & 100 & $20: 80$ & 4 & $100 \pm 1.3$ & $221 \pm 3.5$ & 1.2 & $1,054 \pm 7.6$ \\
\hline SF1 & 20 & $50: 50$ & 4 & $99 \pm 1.0$ & $216 \pm 4.1$ & 1.2 & $1,270 \pm 12.6$ \\
\hline SF2 & 100 & $50: 50$ & 4 & $99 \pm 1.6$ & $230 \pm 5.6$ & 1.3 & $1,118 \pm 9.8$ \\
\hline SF3 & 180 & $50: 50$ & 4 & $102 \pm 2.0$ & $236 \pm 5.1$ & 1.4 & $973 \pm 7.1$ \\
\hline MIX & - & - & 5 & $104 \pm 1.2$ & $260 \pm 6.0$ & 1.6 & $973 \pm 7.1$ \\
\hline SF2 + STR & 100 & $20: 80$ & 4 & $103 \pm 1.0$ & $233 \pm 5.1$ & 1.3 & $1,054 \pm 7.6$ \\
\hline SF1 + AMD & 20 & $50: 50$ & 4 & $95 \pm 1.0$ & $207 \pm 5.4$ & 1.1 & $1,270 \pm 12.6$ \\
\hline SF3 + AMD & 180 & $50: 50$ & 4 & $96 \pm 1.9$ & $228 \pm 4.7$ & 1.4 & $973 \pm 7.1$ \\
\hline
\end{tabular}

${ }^{1}$ These averages are based on the entire experimental period, but MR provision increased gradually during this period.

${ }^{2} \mathrm{SF}=$ solid feed; SEP = ad libitum SF provision with components in separate troughs; MIX = ad libitum SF provision with components mixed together (ratio based on intake of SEP calves); STR = calves with ad libitum provision of long straw in a rack; AMD = automated milk dispenser.

${ }^{3} \mathrm{DMI}=$ target kilograms of DM SF provision from 13 to $29 \mathrm{wk}$.

${ }^{4} \mathrm{R}: \mathrm{C}=$ roughage-to-concentrate ratio.

${ }^{5}$ Each pen contained 5 calves.

the level of utilization of the straw by the calves. These pens were video recorded for $1 \mathrm{~d}$ per week, in wk 18 to 19 and 23 to 24 . The videos were observed using instantaneous scan sampling at a 5-min interval from 0500 to $2200 \mathrm{~h}$. At each scan, calves were scored as (1) not in contact or (2) in contact with the rack, including pulling straw out of the rack, or masticating near and facing the rack, or with straw strands sticking out of the mouth facing the rack or facing away. Data from both weeks at each age were averaged.

\section{Characteristics of Feces}

Characteristics of the feces, reflecting gastrointestinal health status, were recorded when calves were 14 and 25 wk. Two measures were recorded at pen level: presence or absence of fresh diarrhea and presence or absence of clay-like feces. Diarrhea was defined as very thin, watery feces different from normal feces in terms of color. Clay-like feces were defined as thicker and firmer consistency than pudding with a white or gray coloring. Clay-like feces signal ruminal drinking, that is, "the milk is forced into the rumen where it undergoes abnormal decomposition causing physiological disturbances" (van Weeren-Keverling Buisman et al., 1988). These measures were recorded by a veterinarian.

\section{Statistical Analysis}

General. A total of 18 calves were excluded from the study: 7 calves died (infection causing diarrhea or pneumonia), 3 calves were sold (did not grow well on MR), and 8 calves were excluded from behavioral observations at $24 \mathrm{wk}$ (individually housed because of sickness). All data were grouped per pen and age. Pen was the experimental unit. Behavioral data collected

Table 5. Ethogram of observed behaviors

\begin{tabular}{ll}
\hline Behavior & Definition \\
\hline Oral manipulation of pen & $\begin{array}{l}\text { Any oral (nose, lips, or tongue) contact with any aspect of the pen structure including fences, floor, and } \\
\text { trough. }\end{array}$ \\
Tongue playing & $\begin{array}{l}\text { Rolling and unrolling of the tongue inside or outside of the mouth, without oral contact with the } \\
\text { environment }\end{array}$ \\
Leed & Lateral movements of the jaw above a trough with solid feed present or oral contact with solid feed \\
Ruminate & Body not supported by limbs \\
Lie & Nose less than $10 \mathrm{~cm}$ away from an aspect of the environment, with movement of nostrils sometimes, but \\
Sniff & not always, noticeable \\
Play & Any one of the following behaviors: run, jump, buck, head-butt calf, head-butt object \\
Lick calf & Oral contact with body of another calf, without any part of the body being inside the mouth \\
Suck calf & Mouth is around a part of the body (mouth, ear, tail, joint, prepuce) of another calf with suction sounds \\
Groom & Oral contact with any part of own body
\end{tabular}


using instantaneous scan sampling were expressed as proportions of total scans. Separate analyses were carried out for the $4 \times 2$ factorial design (with SEP and MIX), for analyzing effects of providing ad libitum long straw, and for the $2 \times 2$ factorial design. A random pen effect was introduced. The GLIMMIX procedure in SAS (SAS Institute Inc., 2008) was used for all analyses.

$4 \times 2$ Factorial Design with Ad Libitum SF Groups. A generalized linear mixed model (GLMM) with a logit link and specifying the variance as a multiple (dispersion parameter) of the binomial variance function was used for this analysis. To incorporate the ad libitum SF treatments (SEP and MIX) in the $4 \times 2$ factorial design, a dummy experimental factor $\alpha$ with 3 levels was created. The experimental factors for SF level and R:C ratio were extended with 2 extra levels, corresponding to SEP and MIX. Two levels of $\alpha$ corresponded to SEP and MIX, and the third level corresponded to the combinations in the original $4 \times$ 2 factorial design for SF level and R:C ratio. Next, the main effects and interactions for the extended factors for SF level and R:C ratio were nested within factor $\alpha$. Therefore, the first GLMM comprised main effects of $\alpha$, SF level and R:C ratio within $\alpha$, and age and all (up to 4 -way) interactions. Random pen effects were included to account for dependence between repeated measurements of the same pen. Inference was based on pseudolikelihood (Wolfinger and O' Connell, 1993), which is equivalent to penalized quasi-likelihood (Schall, 1991; Breslow and Clayton, 1993; Engel and Keen, 1994). It was checked whether dispersion parameters were equal for both ages. Approximate $F$-tests were employed for the fixed effects (Kenward and Roger, 1997). Significant main effects and interactions were identified, suggesting what relevant contrasts, such as pairwise comparisons, should be inspected in detail next.

The same GLMM was then used with an alternative parameterization to extract test results for the relevant contrasts. All treatments, that is, the combinations of SF level and R:C ratio, as well as SEP and MIX, were included as levels of a single factor $\beta$ with 10 levels. The GLMM comprised main effects and interactions for $\beta$ and age and random effects for pen. Inference for relevant contrasts was obtained with the CONTRAST statement in the GLIMMIX procedure in SAS.

Ad Libitum Long Straw. The STR treatment was paired to pens from the $4 \times 2$ design fed SF2 with R:C 20:80. For this analysis the same GLMM as for the 4 $\times 2$ was used but comprising different fixed effects: presence of straw rack (yes or no), age (15 vs. $24 \mathrm{wk}$ ), and the interaction between both.

$2 \times 2$ Factorial Design. Again, the same GLMM was used, but, for this analysis, the GLMM comprised fixed main effects of SF level (SF1 vs. SF3), MR feed- ing method (bucket vs. AMD), age (15 vs. 24 wk), and all possible interactions.

Characteristics of Feces. The prevalence (at pen level) of each type of feces (i.e., diarrhea and clay like) was analyzed using Fisher's exact test (SAS routine PROC FREQ).

\section{RESULTS}

\section{SF Level and SF Composition}

Mean percentage total scans for behaviors of calves fed different $\mathrm{SF}$ levels with different $\mathrm{R}: \mathrm{C}$ ratios are shown in Table 6. Only SF4 with R:C 50:50 considerably reduced the frequency of abnormal oral behaviors, that is, manipulation of the pen and tongue playing. The frequency of feeding behaviors increased with SF level but was unaffected by $\mathrm{R}: \mathrm{C}$ ratio. The frequency of rumination increased with SF level, although this observation was mostly restricted to R:C 50:50, as opposed to 20:80.

A main effect of age was found on the frequency of oral manipulation of the pen $(P=0.014)$, sucking pen mates $(P<0.001)$, and grooming $(P<0.001)$. At 24 wk, calves orally manipulated the pen less $(6.8 \pm 0.6 \%)$ than at $15 \mathrm{wk}(8.1 \pm 0.5 \%)$. The frequency of both sucking pen mates and grooming also decreased from 15 to 24 wk (suck: $1.2 \pm 0.1$ and $0.4 \pm 0.1 \%$; groom: 3.0 \pm 1.8 and $1.8 \pm 0.1 \%$, at 15 and 24 wk, respectively). For play behaviors, an interaction between $\mathrm{R}$ : $\mathrm{C}$ ratio and age was found $(P=0.023)$, with calves fed R:C 20:80 decreasing their play frequency from 15 wk $(2.3$ $\pm 0.3 \%)$ to $24 \mathrm{wk}(1.0 \pm 0.2 \%)$. Pairwise comparisons of SEP and MIX with SF level on the one hand, and $\mathrm{R}: \mathrm{C}$ ratio on the other hand, are described in Table 7 . The MIX and SEP calves did not differ for any of the behaviors recorded in this study. For abnormal oral behaviors, MIX and SEP calves were similar to SF3 and SF4 and to pens fed R:C 50:50. For feeding behaviors, MIX and SEP calves were similar to SF3 and SF4. The MIX and SEP pens showed higher frequencies of feeding than pens fed both R:C 20:80 and 50:50. For rumination, MIX and SEP calves were only similar to SF4 and had higher rumination frequencies than pens fed R:C 50:50 and 20:80. Daily variations in frequency of oral manipulation of the pen, tongue playing, and lying are shown in Figure 2.

\section{Intake of Calves in SEP and MIX}

Total kilograms of fresh product intakes were 425.3 \pm 9.0 and $459.9 \pm 19.0$ for MIX and SEP from 13 to 29 wk of age. For SEP calves this intake translates to $294.1 \pm 9.6 \mathrm{~kg}$ of DM. In comparison, intakes were 
$241.9 \pm 0.8$ and $232.4 \pm 0.5 \mathrm{~kg} / \mathrm{d}$ of DM for SF4 calves fed R:C 20:80 and 50:50, respectively, from 13 to $29 \mathrm{wk}$ of age. At 15 wk of age, SEP calves consumed 1,146 \pm $125.1,368 \pm 37.4$, and $134 \pm 16.0 \mathrm{~g} / \mathrm{d}$ of DM concentrate, maize silage, and straw. At 24 wk of age, SEP calves consumed 2,325 $\pm 63.3,644 \pm 66.3$, and $313 \pm$ $26.2 \mathrm{~g} / \mathrm{d}$ of DM concentrate, maize silage, and straw. The average percentages (on DM basis) of concentrate, maize silage, and straw selected by SEP calves were rather constant between ages and were $70.8 \pm 0.4 \%$, $20.2 \pm 0.4 \%$, and $9.1 \pm 0.3 \%$.

\section{Ad Libitum Long Straw}

The provision of ad libitum long straw on top of a conventional veal diet resulted in lower levels of oral manipulation of the pen and tongue playing (Table 8). An interaction between the presence of a straw rack and age was found for feeding, rumination, and licking other calves. The STR calves were observed feeding less often at 15 than $24 \mathrm{wk}$ and more so than calves without a straw rack at 24 wk of age (Table 8 ). The STR calves showed more rumination at both ages compared with calves without ad libitum straw (Table 8). Finally, both of these groups of calves changed the frequency at which they licked their pen mates, but in opposite directions, with STR calves licking less and calves without a straw rack licking more at 15 compared with 24 wk of age (Table 8 ). The use of the straw in the rack (percent observations), derived from video observations, is shown in Figure 3. This graph shows 2 rack-usage peaks at 18 to $19 \mathrm{wk}$, one before the afternoon feed $(1600 \mathrm{~h})$ and one just before the lights were switched off $(2200 \mathrm{~h})$, and 3 rack-usage peaks at 23 to 24 wk: the same 2 as for 18 to 19 wk plus one after the morning feed. The usage of straw was approximately $650 \mathrm{~g} / \mathrm{d}$ per calf, including spilling the straw on the floor as well as consumption.

\section{SF Level and MR Feeding Method}

Milk replacer feeding method affected sniffing frequency, with AMD calves showing less sniffing than bucket-fed calves (Table 9). An interaction between MR feeding method and age was found for tongue playing and lying. At $15 \mathrm{wk}$ of age, AMD calves tongue played less than bucket-fed calves. However, AMD calves increased their tongue-playing frequency from 15 to $24 \mathrm{wk}$ of age, resulting in similar levels of tongue playing between these 2 groups at 24 wk (Table 9 ). The AMD calves decreased their lying frequency from 15 to $24 \mathrm{wk}$, in such a way that they were lying less than bucket-fed calves at $24 \mathrm{wk}$ but not at $15 \mathrm{wk}$ (Table 9 ). Milk replacer feeding did not have an effect on any of the other behaviors monitored (Table 9). An age effect 
Table 7. Frequency of behaviors (mean percentage of total scans) and SEM, averaged over 2 ages (15 and 24 wk) and observed in veal calves fed different levels of solid feed (SF) with different roughage-to-concentrate (R:C) ratios, or offered ad libitum (AL) feed ${ }^{1}$

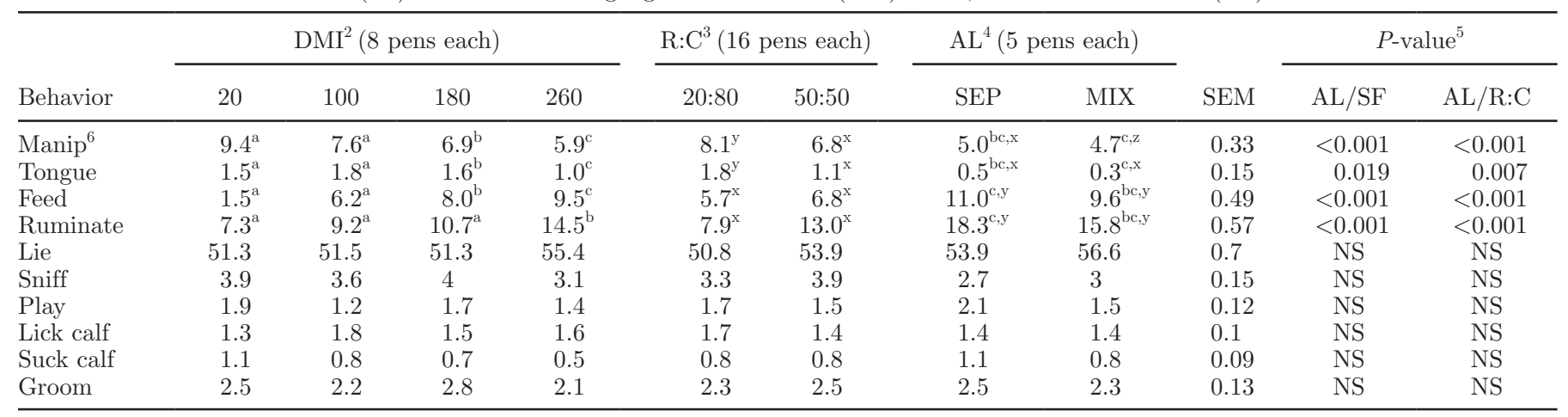

${ }^{\mathrm{a}-\mathrm{c}}$ Means within a row with no common superscripts differ $(P<0.05)$ : AL/SF.

${ }^{\mathrm{x}-\mathrm{z}}$ Means within a row with no common superscripts differ $(P<0.05)$ : AL/R:C.

${ }^{1}$ Behavior was recorded using instantaneous scan sampling. Pairwise comparisons are shown between AL treatments and SF level on the one hand and R:C on the other hand. Milk replacer was provided in such a way that aimed for equal rates of carcass gain across treatments (excluding SEP and MIX).

${ }^{2} \mathrm{DMI}=$ target kilograms of DM SF provision from 13 to $29 \mathrm{wk}$.

${ }^{3}$ Roughage included $50 \%$ maize silage and 50\% chopped wheat straw, on a DM basis.

${ }^{4} \mathrm{SEP}=$ ad libitum SF provision with components in separate troughs; MIX = ad libitum SF provision with components mixed together (ratio based on intake of SEP calves).

${ }^{5} \mathrm{AL} / \mathrm{SF}=$ pairwise comparisons between $\mathrm{AL}$ treatments and $\mathrm{SF}$ level; $\mathrm{AL} / \mathrm{R}: \mathrm{C}=$ pairwise comparisons between $\mathrm{AL}$ treatments and $\mathrm{R}: \mathrm{C}$ ratio.

${ }^{6}$ Manip = oral manipulation of pen.

was found for sniffing and grooming (Table 9), with calves increasing sniffing ( 15 wk: $3.4 \pm 0.3 \%$; 24 wk: 4.2 $\pm 0.3 \%$ ) and decreasing grooming (15 wk: $3.3 \pm 0.4 \%$; 24 wk: $1.9 \pm 0.2 \%)$ with age.

\section{Characteristics of Feces}

The presence of diarrhea within a pen seemed affected by SF level (including SEP and MIX) but not by $\mathrm{R}$ :C ratio, provision of ad libitum straw, or MR feeding method (Table 10). The SF1 calves showed the highest levels of diarrhea at both 14 and 25 wk of age. The prevalence of clay-like feces was not affected by any of the feeding treatments.

\section{DISCUSSION}

This study aimed to investigate the effect of various diets on veal calf behavior and feces characteristics reflecting gastrointestinal health status. Abnormal oral behaviors, feeding behavior, and rumination were affected by changes in SF level and $\mathrm{R}: \mathrm{C}$ ratio, including SEP, MIX, and STR treatments. Increasing SF provision when the composition was R:C 20:80 had little effect on rumination and abnormal oral behaviors, relative to 50:50. The only diet that seemed to substantially reduce the frequency of oral manipulation was SF4 with R:C 50:50. This is also the diet that resulted in a high level of rumination (i.e., approximately 20\%). A rumination frequency of $20 \%$ was also reported in previous work with similar behavioral observation methods (Webb et al., 2013) and in a study where calves were given ad libitum access to MR and $5 \mathrm{SF}$ components (Webb et al., 2014). Providing SF with R:C 50:50 instead of 20:80 increased the frequency of rumination and subsequently decreased the frequency of abnormal oral behaviors.

Consistent with previous findings, tongue playing seemed less associated with feeding and activity times, than oral manipulation of the pen (Webb et al., 2012). This may suggest that these 2 forms of abnormal oral behavior have 2 distinct underlying motivations. We suggest that tongue playing may be directly related to chewing activity (feeding and rumination) and, therefore, is frequent around feeding times as well as during periods when calves normally ruminate (i.e., between feeding times: Veissier et al., 1998; Webb et al., 2012). In contrast, oral manipulation of the pen might be related to anticipation (arousal) of an up-coming meal (Mason, 1991; Lawrence and Terlouw, 1993) or to positive feedback and reinforcement caused by the meal being too short and not satisfying eating motivation of veal calves (Lawrence et al., 1993). This would explain why oral manipulation of the pen is most frequent before and after feeding times.

Calves provided with ad libitum SF, with components in separate troughs (SEP), consumed approximately $2.3 \mathrm{~kg} / \mathrm{d}$ of DM concentrate and $0.9 \mathrm{~kg} / \mathrm{d}$ of DM roughage at 24 wk of age. Previous work on veal calves revealed an average voluntary intake of hay of $1.2 \mathrm{~kg}$ of $\mathrm{DM} / \mathrm{d}$ at 27 wk of age (Webb et al., 2013). Moreover, 
15 wk

$24 \mathrm{wk}$

Oral manipulation of pen
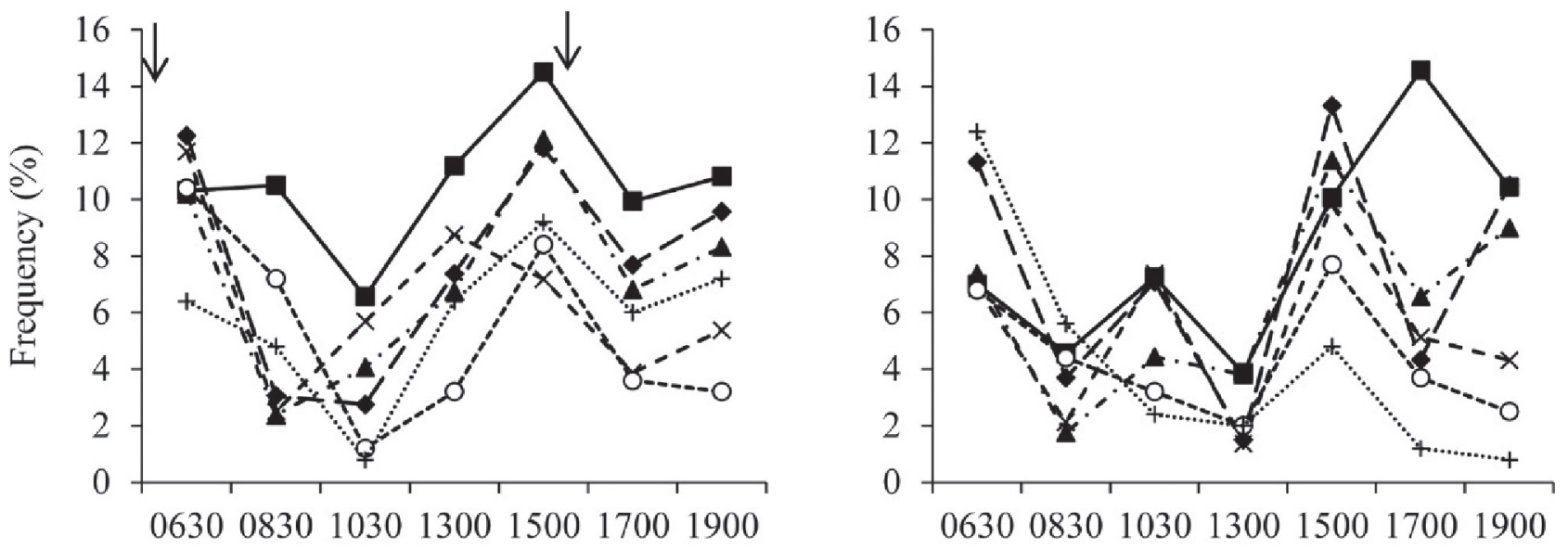

Tongue playing
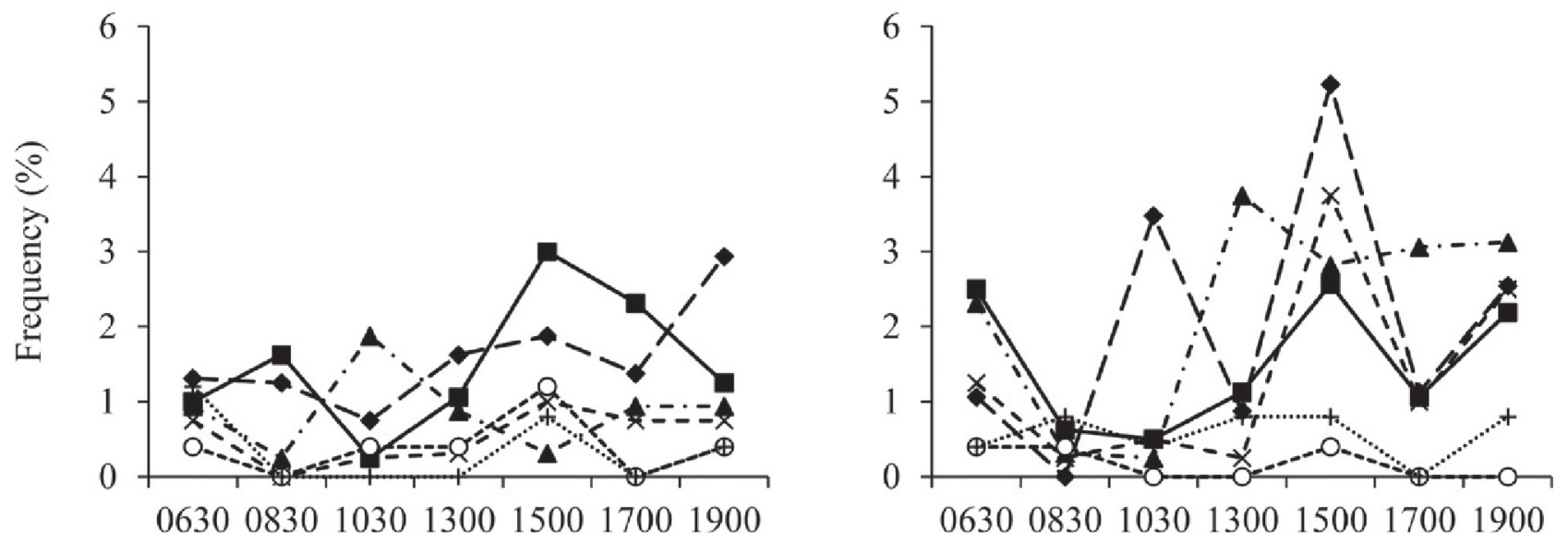

Lie
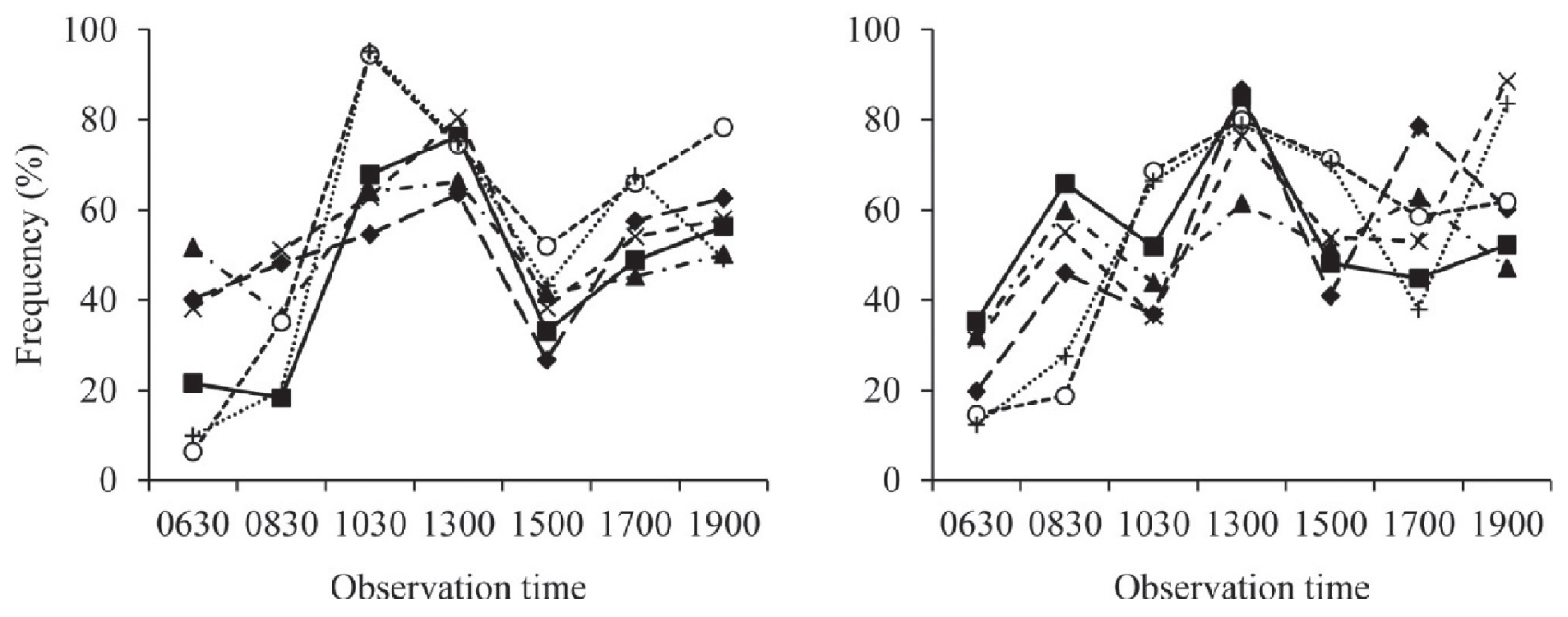

Figure 2. Frequency (percentage of total scans) at which calves were observed manipulating the environment, performing tongue movements, and lying throughout the day at 15 and $24 \mathrm{wk}$ of age in calves fed $20,100,180$, or $260 \mathrm{~kg}$ of solid feed $(\boldsymbol{\square}$, $\boldsymbol{\nabla}, \boldsymbol{\Lambda}$, and $\times$, respectively) and in calves fed ad libitum solid feed with ration components mixed $(\bigcirc)$ or in separate troughs $(+)$. Arrows in the first graph indicate the start of feeding (0600 and $1600 \mathrm{~h})$. 


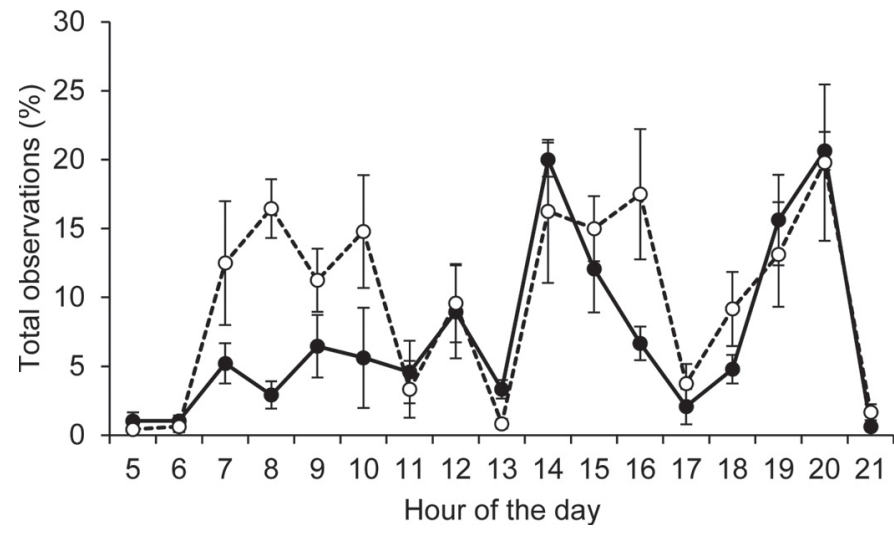

Figure 3. Average percentage of observations (out of 60: 12 scans on 5 calves) within a pen using the straw rack between 0500 and 2200 $\mathrm{h}$ at 18 to $19 \mathrm{wk}$ (continuous line) and 23 to $24 \mathrm{wk}$ of age (dashed line). These data are based on 4 pens ( 5 calves per pen), with 2 repetitions at each age ( 1 wk apart). The error bars show the variation between pens.

in a previous study, we found a total average voluntary intake of $3.2 \mathrm{~kg}$ of $\mathrm{DM} / \mathrm{d}$, with $2.1 \mathrm{~kg}$ of $\mathrm{DM} / \mathrm{d}$ concentrate and $1.1 \mathrm{~kg}$ of $\mathrm{DM} / \mathrm{d}$ roughage, in 27-wk-old calves with ad libitum access to MR, concentrate, hay, maize silage, and straw (Webb et al., 2014). Despite large differences in MR intake and experimental setup, calves seem to consume similar amounts of concentrate (if present) and roughage in these studies. The SF4 calves had the closest intake, although lower, to that of
MIX and SEP calves. Moreover, MIX and SEP calves consumed on average $70 \%$ concentrate, which makes these 2 ad libitum treatments most similar to SF4 with R:C 20:80 in terms of SF intake. For most behaviors and for feces measurements, MIX and SEP calves were similar to SF4 calves despite the MR and SF intakes being different, that is, MR intake was higher for MIX and SEP calves, which had the same MR provision as SF3 calves with R:C 50:50. In terms of tongue playing and oral manipulation of the pen, MIX and SEP calves were more similar to calves fed R:C 50:50 compared with 20:80. This could be explained by R:C 20:80 not stimulating optimum rumination in calves and, therefore, not being sufficient to prevent the development of abnormal oral behaviors, such as tongue playing and oral manipulation of the pen. No differences in behavior were observed between SEP and MIX calves, which is contrary to previous findings in dairy calves, showing calves with a mixed ration spent more time feeding than calves with separate components (Miller-Cushon et al., 2013b). These authors also reported no differences in intake between these 2 feed presentation methods (Miller-Cushon et al., 2013a), which is in contradiction with the present study where SEP calves consumed more than MIX calves at 18, 19, 23, and 25 wk of age (Berends, 2014). The findings in the present study could relate to MIX calves receiving the composition selected by SEP calves in the previous week, which means they were a week behind in terms of composition. However,

Table 8. Frequency of behaviors (mean percentage of total scans) and SEM, observed in veal calves with or without a straw rack ( 8 pens with 5 calves $^{1}$

\begin{tabular}{|c|c|c|c|c|c|}
\hline \multirow[b]{2}{*}{ Behavior } & \multicolumn{2}{|c|}{ Straw rack (4 pens each) } & \multirow[b]{2}{*}{ SEM } & \multicolumn{2}{|c|}{$P$-value } \\
\hline & No & Yes & & Straw rack & Straw rack $\times$ age \\
\hline Manip $^{2}$ & 7.8 & 4.0 & 0.71 & 0.021 & NS \\
\hline Tongue & 2.0 & 0.4 & 0.36 & 0.027 & NS \\
\hline \multicolumn{6}{|l|}{ Feed } \\
\hline $15 \mathrm{wk}$ & $8.1^{\mathrm{a}, \mathrm{x}}$ & $8.5^{\mathrm{a}, \mathrm{x}}$ & 1.37 & & 0.021 \\
\hline $24 \mathrm{wk}$ & $4.0^{\mathrm{a}, \mathrm{x}}$ & $15.8^{\mathrm{b}, \mathrm{y}}$ & & & \\
\hline \multicolumn{6}{|l|}{ Ruminate } \\
\hline $15 \mathrm{wk}$ & $8.6^{\mathrm{a}, \mathrm{x}}$ & $13.0^{\mathrm{b}, \mathrm{x}}$ & 1.18 & & 0.041 \\
\hline $24 \mathrm{wk}$ & $6.0^{\mathrm{a}, \mathrm{x}}$ & $16.5^{\mathrm{b}, \mathrm{x}}$ & & & \\
\hline Lie & 51.9 & 57.1 & 1.79 & NS & NS \\
\hline Sniff & 3.4 & 3.1 & 0.21 & NS & NS \\
\hline Play & 1.3 & 1.1 & 0.31 & NS & NS \\
\hline \multicolumn{6}{|l|}{ Lick calf } \\
\hline $15 \mathrm{wk}$ & $2.1^{\mathrm{a}, \mathrm{x}}$ & $1.2^{\mathrm{a}, \mathrm{x}}$ & 0.21 & & 0.003 \\
\hline $24 \mathrm{wk}$ & $1.2^{\mathrm{a}, \mathrm{y}}$ & $1.9^{\mathrm{a}, \mathrm{y}}$ & & & \\
\hline Suck calf & 0.5 & 0.5 & 0.11 & NS & NS \\
\hline Groom & 1.9 & 3.1 & 0.27 & NS & NS \\
\hline
\end{tabular}

${ }^{a, b}$ When there is an interaction, means with different superscripts in a row differ $(P<0.05)$.

${ }^{\mathrm{x}, \mathrm{y}}$ When there is an interaction, means with different superscripts in a column for one behavior differ $(P<$ $0.05)$.

${ }^{1}$ Behavior was recorded using instantaneous scan sampling. $P$-values for the fixed main effect of the presence of a straw rack and the interaction between presence of straw rack and age are shown.

${ }^{2}$ Manip $=$ oral manipulation of pen 
Table 9. Frequency of behaviors (mean percentage of total scans) and SEM, observed in veal calves fed milk replacer with an automated milk dispenser (AMD) or a bucket and 1 of 2 solid-feed (SF) levels ${ }^{1}$

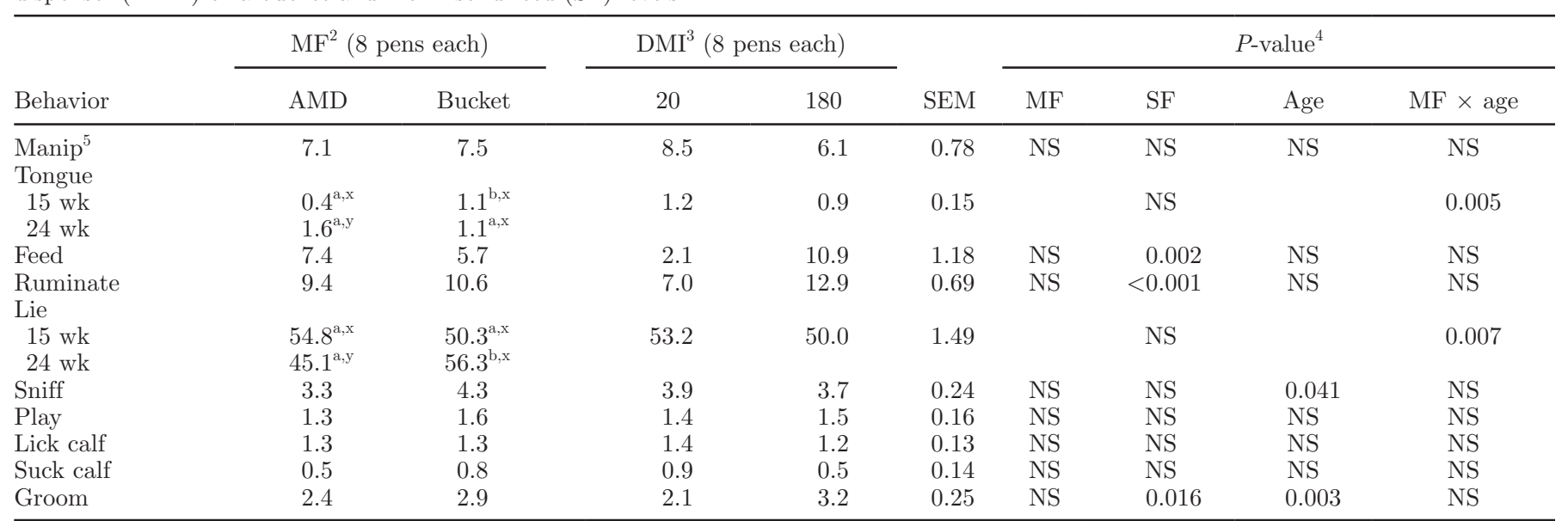

${ }^{\mathrm{a}, \mathrm{b}}$ When there is an interaction, means with different superscripts in a row differ $(P<0.05)$.

${ }^{\mathrm{x}, \mathrm{y}}$ When there is an interaction, means with different superscripts in a column for one behavior differ $(P<0.05)$.

${ }^{1}$ Behavior was recorded using instantaneous scan sampling. No interaction with SF level was found. Milk replacer (MR) was provided in such a way that aimed for equal rates of carcass gain across treatments.

${ }^{2} \mathrm{MF}=\mathrm{MR}$ feeding method.

${ }^{3} \mathrm{DMI}=$ target kilograms of DM SF provision from 13 to $29 \mathrm{wk}$.

${ }^{4} \mathrm{MF} \times$ age $=$ interaction between MR feeding method and age.

${ }^{5}$ Manip $=$ oral manipulation of pen.

differences in composition across weeks were small so this is unlikely. A more likely explanation is that MIX calves developed aversions to their monotonous ration during meals, as suggested by Provenza et al. (1996).

Calves in pens fitted with a straw rack mostly used the straw after the morning meal and before and after the afternoon meal, which coincides with the times at which calves in pens not fitted with straw racks were most active. Ad libitum provision of long straw to calves otherwise fed a relatively low level of SF (i.e., SF2: $100 \mathrm{~kg}$ of DM) with R:C 20:80 resulted in similar levels of abnormal oral behaviors and chewing activity as in calves fed ad libitum SF (SEP and MIX), based on mean comparisons. This reinforces the idea that coarse roughages are beneficial in terms of increasing chewing activity and decreasing abnormal oral behaviors in veal calves (Mattiello et al., 2002; Webb et al., 2013). Moreover, ad libitum provision of straw in racks stimulates a more natural foraging behavior because (1) calves have to pull straw out of the rack, similarly to pulling grass from the ground, and (2) calves can consume roughage throughout the day and night (e.g., Le Neindre and Petit, 1975). The benefits of straw racks have been suggested in pigs for decreasing stereotypic

Table 10. Prevalence of diarrhea and clay-like feces (at pen level) within different feeding treatments at 14 and 25 wk of age

\begin{tabular}{|c|c|c|c|c|c|c|c|c|c|c|c|c|}
\hline \multirow[b]{2}{*}{ Item } & \multicolumn{4}{|c|}{$\begin{array}{c}\mathrm{DMI}^{1} \\
\text { (8 pens each) }\end{array}$} & \multicolumn{2}{|c|}{$\begin{array}{c}\text { R: } \mathrm{C}^{2} \\
\text { (16 pens each) }\end{array}$} & \multicolumn{2}{|c|}{$\begin{array}{c}\mathrm{AL}^{3} \\
(5 \text { pens each })\end{array}$} & \multicolumn{2}{|c|}{$\begin{array}{c}\text { Straw rack } \\
\text { (4 pens each) }\end{array}$} & \multicolumn{2}{|c|}{$\begin{array}{c}\mathrm{MF}^{4} \\
\text { (8 pens each) }\end{array}$} \\
\hline & 20 & 100 & 180 & 260 & $20: 80$ & $50: 50$ & MIX & SEP & No & Yes & AMD & Bucket \\
\hline \multicolumn{13}{|l|}{14 wk } \\
\hline Diarrhea & $75^{\mathrm{a}}$ & $13^{\mathrm{b}}$ & $0^{\mathrm{b}}$ & $13^{\mathrm{b}}$ & 38 & 13 & $0^{\mathrm{b}}$ & $0^{\mathrm{b}}$ & 25 & 0 & 50 & 25 \\
\hline Clay like & 13 & 13 & 0 & 0 & 6 & 6 & 0 & 0 & 25 & 0 & 25 & 13 \\
\hline \multicolumn{13}{|l|}{$25 \mathrm{wk}$} \\
\hline
\end{tabular}


behavior in sows (Stewart et al., 2011), and stimulating exploratory behavior (Zwicker et al., 2012) and reducing gastric ulceration (Di Martino et al., 2013) in finishing pigs. Straw racks most likely offer a simple welfareimprovement method for veal calves too. The benefit of straw in veal-production systems is that it does not add much nutritional value or iron to the diet. The negative effect of coarse roughage sources on gastrointestinal health, however, should not be taken lightly. Straw has previously been associated with an exacerbation of abomasal damage relative to calves fed only MR or calves fed MR and a less abrasive roughage source (i.e., maize silage or hay; Mattiello et al., 2002; Webb et al., 2013). Veissier et al. (1998) showed that if calves are initially fed concentrate (gradually increased from 100 to $500 \mathrm{~g} / \mathrm{d}$ ) without roughage at a young age, thereby promoting certain aspects of early rumen development (i.e., papillae development), then the provision of straw later on (i.e., $450 \mathrm{~g} / \mathrm{d}$ from $7 \mathrm{wk}$ of age onward) may not exacerbate abomasal damage compared with calves fed only MR. In the present study, straw racks were only fitted from 13 wk onward, and no exacerbation of abomasal damage was observed (unpublished data).

Milk replacer feeding method had an effect on the frequency of tongue playing. Along with oral manipulation of the pen, tongue playing is thought to stem from frustration resulting from limited chewing opportunity, whether feeding or rumination (Mattiello et al., 2002; Webb et al., 2012, 2013). Other studies have also suggested a link between tongue playing and sucking on a teat (Seo et al., 1998). The present study aimed to verify whether tongue playing was related to chewing or sucking, and a relationship to both of these motivations was found. Rumination was especially affected by roughage amount, rather than total SF amount: higher levels of SF in calves fed R:C 20:80 had little effect on rumination frequency. Only in calves fed R:C 50:50 did SF level have an effect on rumination frequency, suggesting concentrate had little effect on rumination. This is logical because one of the main functions of rumination is to reduce the size of feed particles in the rumen before passage into the abomasum. Therefore, concentrate, with its small particle size, is unlikely to stimulate much rumination. A similar (although inverted) pattern of results was found for tongue playing, suggesting rumination and tongue playing are linked. Indeed, tongue playing was only affected by roughage provision and ad libitum provision of straw and not by total SF provision. In addition, low levels of tongue playing were observed in AMD calves at $15 \mathrm{wk}$ of age, but not at $24 \mathrm{wk}$, which may suggest that tongue playing is also related to sucking. It is unlikely that MR feeding frequency played a role here (van den Borne, Friesland Campina,
Wageningen, the Netherlands, personal communication). Tongue playing can take 2 general forms: that is, tongue rolling inside the mouth or tongue rolling outside of the mouth (personal observation). These 2 forms could potentially stem from different motivations: that is, sucking and ruminating. Tongue rolling inside the mouth looks similar to a sucking movement (some calves tilt their head backward while performing this behavior), whereas tongue rolling outside of the mouth could mimic the tongue movement used to pull grass up from the ground. To confirm this hypothesis, studies would need to record these 2 types of abnormal tongue movements separately and see whether they are differentially affected by roughage provision and the availability of a teat. Moreover, tongue rolling inside, as opposed to outside, the mouth should be more frequent in young calves (up to 8 wk of age), because sucking motivation is likely to be stronger at a young age (Wiepkema, 1987). Finally, observing both tongue movements in the same individual at different times of day may also point to separate motivations.

Playing frequency was affected by the composition of the SF, with calves fed SF with R:C 20:80 showing a decrease in playing frequency with age. Playing is considered an indicator of positive welfare or luxury behavior in animals (Lawrence, 1987). This could be an indication that calves with R:C 20:80 experienced a decrease in welfare. However, no age differences were observed for the frequencies of rumination or abnormal oral behaviors, so this hypothesized decrease in welfare may have been related to (gastrointestinal) health rather than behavior.

The frequency of lying, sniffing, licking a calf, sucking a calf, and grooming were unaffected by aspects of the diet in the current study. Lying seems more linked to the housing system than to SF provision, with grouphoused calves (i.e., 40-80 calves per pen) fed MR via AMD lying more than conventional group-housed (i.e., 5 to 7 calves per pen) or individually housed calves (Bokkers and Koene, 2001). In the present study we observed a decrease in lying (i.e., increase in activity) in AMD calves from 15 to 24 wk of age. Although no significant age effect was observed for lying behavior for other treatments, SEP and MIX calves seem to have also decreased their lying from 15 to 24 wk of age (Figure 2). Calves at pasture naturally become more active, that is, spend less time lying, spend more time standing, and move across larger distances, as they grow older (0 to 8 wk of age; Wood-Gush et al., 1984), and we may assume that calves continue to become more active from 15 to 24 wk of age. In that case, we can speculate that a failure to observe a decrease in lying in the other treatments could potentially indicate abnormal behavior and might be a warning sign for 
poor welfare. Alternatively, AMD calves may have been more active due to competition around the AMD or due to an increased number of MR feeding times relative to bucket-fed calves. Therefore, differences in lying may have been unrelated to differences in welfare.

Sniffing could be a measure of exploration, which was previously related to welfare in beef cattle (Westerath et al., 2009). Sniffing could indicate feed searching and was thus expected to be performed more frequently in calves with lower SF provisions, but this was not found. This might be a consequence of this study adjusting MR provision for equal growth between treatments, which may have resulted in similar levels of satiety (e.g., similar nutrient uptake) despite differences in SF provision. It is unknown how rumen fill versus abomasum fill affects satiety. Licking pen mates may also signal feed searching and was linked to veal calf diets in past studies (Mattiello et al., 2002; Webb et al., 2013). Licking self (groom) or other calves was of particular interest in individually housed calves that seemed to lick themselves excessively (Bokkers and Koene, 2001) and in individual- and group-housed calves that developed hairballs in their rumen (Toofanian, 1976; Bokkers and Koene, 2001). The present study, however, failed to find an association between diet and licking of hair. Therefore, excessive licking of hair may be more related to housing than feeding conditions. Moreover, a causal link between the frequency of hair licking and hairball prevalence in veal calves is not corroborated (Morisse et al., 1999; Webb et al., 2013).

Sucking of body parts of other calves, including prepuce, nose, tail, ears, and joints, also referred to as cross-sucking (de Passillé, 2001), and urine drinking are, along with the monitoring of drinking behavior and health, important reasons why veal calves typically spend the first few weeks of the fattening period in individual pens. Cross-sucking seems to be triggered by ingestion of milk (Lidfors, 1993). Minimizing crosssucking can be achieved by reducing MR flow out of a teat, providing dry teats or providing hay alongside MR in dairy calves (de Passillé, 2001). In the present study, calves fed via an AMD had MR available at least 3 times a day, as opposed to twice a day in bucket-fed calves, had the opportunity to suck, and had a reduced MR flow and abomasal fill compared with bucket-fed calves. Therefore, we hypothesized that cross-sucking would be reduced in calves fed MR via an AMD as opposed to open buckets. We also hypothesized that cross-sucking would be reduced in calves fed more roughage. However, neither of these hypotheses was supported by the current study. In fact, very low levels of cross-sucking were observed in all treatments, consistent with Smits and de Wilt (1991), and this possibly concealed treatment differences. Cross-sucking is more frequent in young calves and may not be an important behavior past 8 wk of age, when calves start making the switch from preruminants to full ruminants and when chewing motivation may override sucking motivation (Wiepkema, 1987; Margerison et al., 2003).

Diarrhea was especially high in calves fed the lowest levels of SF (i.e., SF1 $=20 \mathrm{~kg}$ of DM) and, thus, the highest amounts of MR, at both 14 and 25 wk of age. However, no differences in diarrhea incidence were found between the $2 \mathrm{R}: \mathrm{C}$ ratios or the $2 \mathrm{MR}$ feeding methods. It is unknown whether high diarrhea incidence was caused by low SF provision, high MR provision, or a combination of these 2 factors. Diarrhea incidence was not increased in dairy calves given ad libitum access to MR, compared with calves fed restricted MR (Borderas et al., 2009), implying MR provision may not be the main cause for diarrhea in the present study. However, in the study by Borderas et al. (2009), calves were fed MR via AMD not buckets, and this may reduce diarrhea incidence by allowing more MR feedings. Clay-like feces signal ruminal drinking, that is, "the milk is forced into the rumen where it undergoes abnormal decomposition causing physiological disturbances" (van Weeren-Keverling Buisman et al., 1988). This condition is thought to be related to feeding milk from open buckets and, depending on SF sources fed and age of the animal, can cause severe bloating (Wise and Anderson, 1939; van Weeren-Keverling Buisman et al., 1988). Recent work, however, seems to rule out any effect of SF and concentrate provision or MR volume on the prevalence of ruminal drinking and instead suggests investigating effects of stress, feeding frequency, and MR composition (Berends, 2014). Slower ingestion of milk from a teat was hypothesized to reduce the incidence of ruminal drinking, but this was not observed in the present study; no effect of MR feeding method was observed on the incidence of clay-like feces.

\section{CONCLUSIONS}

Increased roughage provision, but not concentrate, increased rumination and decreased tongue playing. This suggest that future veal diets should include more roughage, regardless of concentrate amount, if rumination is to be stimulated and abnormal oral behavior prevalence reduced, and subsequently welfare improved. Moreover, the similarities in how diet characteristics affect rumination and tongue playing (although inversely) as well as the similarity in timing of these 2 behaviors throughout the day point to a causal link between the 2 . In other words, tongue rolling may develop as a direct consequence of insufficient rumination, instead of feeding behavior per se. The STR calves had similar levels of rumination and abnormal oral behaviors as MIX and 
SEP calves. Therefore, offering ad libitum long straw may offer a simple strategy to improve veal-calf welfare. Offering MR via an AMD did not seem to affect behavior much compared with calves fed MR in buckets, except that tongue playing was reduced at $15 \mathrm{wk}$. Tongue playing was related to both roughage amount and AMD feeding, suggesting 2 separate motivations underlying the development of this behavior. Only SF level affected aspects of feces; SF1 calves had the highest diarrhea incidence. The prevalence of clay-like feces, which signals ruminal drinking, was unaffected by diet.

\section{ACKNOWLEDGMENTS}

The authors thank the Division for Earth and Life Sciences (ALW) of the Netherlands Organization for Scientific Research (NWO, The Hague, the Netherlands), and the Product Board Animal Feed (The Hague, the Netherlands) for financially supporting this research. In addition, they are grateful to the caretakers at the Scherpenzeel experimental facilities, belonging to the VanDrie Group (Klaas Boeder, Bart Evers, and Ewart van Voorst), and to Bert Beukers and André Jansen. Finally, the authors thank Joswita van der Velde and Teun Keizer (Wageningen University) for help with the experimental procedures.

\section{REFERENCES}

Balch, C. C. 1971. Proposal to use time spent chewing as an index of the extent to which diets for ruminants possess the physical property of fibrousness characteristic of roughage. Br. J. Nutr. 26:383-392.

Berends, H. 2014. Nutrient utilization, dietary preferences, and gastrointestinal development in veal calves. Interactions between solid feed and milk replacer. PhD Thesis. Wageningen Univ., Wageningen, the Netherlands.

Berends, H., J. J. G. C. van den Borne, H. Mollenhorst, C. G. van Reenen, E. A. M. Bokkers, and W. J. J. Gerrits. 2014. Utilization of roughages and concentrates relative to that of milk replacer increases strongly with age in veal calves. J. Dairy Sci. 97:6475-6484.

Berends, H., C. G. van Reenen, N. Stockhofe-Zurwieden, and W. J. J. Gerrits. 2012. Effects of early rumen development and solid feed composition on growth performance and abomasal health in veal calves. J. Dairy Sci. 95:3190-3199.

Bokkers, E. A. M., and P. Koene. 2001. Activity, oral behaviour and slaughter data as welfare indicators in veal calves: A comparison of three housing systems. Appl. Anim. Behav. Sci. 75:1-15.

Borderas, T. F., A. M. de Passillé, and J. Rushen. 2009. Feeding behavior of calves fed small or large amounts of milk. J. Dairy Sci 92:2843-2852.

Breslow, N. E., and D. G. Clayton. 1993. Approximate inference in generalized linear mixed models. J. Am. Stat. Assoc. 88:9-25.

Brscic, M., L. F. M. Heutinck, M. Wolthuis-Fillerup, N. Stockhofe, B. Engel, E. K. Visser, F. Gottardo, E. A. M. Bokkers, B. J. Lensink, G. Cozzi, and C. G. van Reenen. 2011. Prevalence of gastrointestinal disorders recorded at postmortem inspection in white veal calves and associated risk factors. J. Dairy Sci. 94:853-863.

de Passillé, A. M. 2001. Sucking motivation and related problems in calves. Appl. Anim. Behav. Sci. 72:175-187. de Passillé, A. M., and J. Rushen. 1997. Motivational and physiological analysis of the causes and consequences of non-nutritive sucking by calves. Appl. Anim. Behav. Sci. 53:15-31.

Di Martino, G., K. Capello, A. Scollo, F. Gottardo, A. L. Stefani, F. Rampin, E. Schiavon, S. Marangon, and L. Bonfanti. 2013. Continuous straw provision reduces prevalence of oesophago-gastric ulcer in pigs slaughtered at $170 \mathrm{~kg}$ (heavy pigs). Res. Vet. Sci. 95:1271-1273.

Engel, B., and A. Keen. 1994. A simple approach for the analysis of generalized linear mixed model. Stat. Neerl. 48:1-22.

Froberg, S., and L. Lidfors. 2009. Behaviour of dairy calves suckling the dam in a barn with automatic milking or being fed milk substitute from an automatic feeder in a group pen. Appl. Anim. Behav. Sci. 117:150-158.

Kahyani, A., G. R. Ghorbani, M. Khorvash, S. M. Nasrollahi, and K. A. Beauchemin. 2013. Effects of alfalfa hay particle size in highconcentrate diets supplemented with unsaturated fat: Chewing behavior, total-tract digestibility, and milk production of dairy cows. J. Dairy Sci. 96:7110-7119.

Kenward, M. G., and J. H. Roger. 1997. Small sample inference for fixed effects from restricted maximum likelihood. Biometrics 53:983-997.

Lawrence, A. B. 1987. Consumer demand theory and the assessment of animal welfare. Anim. Behav. 35:293-295.

Lawrence, A. B., and E. M. C. Terlouw. 1993. A review of behavioralfactors involved in the development and continued performance of stereotypic behaviors in pigs. J. Anim. Sci. 71:2815-2825.

Lawrence, A. B., E. M. C. Terlouw, and I. Kyriazakis. 1993. The behavioural effects of undernutrition in confined farm animals. Proc. Nutr. Soc. 52:219-229.

Le Neindre, P., and M. Petit. 1975. Nombre de tétées et temps de paturage des veaux dans les troupeaux de vaches allaitantes. Ann. Zootech. 24:553-558.

Leruste, H., M. Brscic, G. Cozzi, B. Kemp, M. Wolthuis-Fillerup, B. J. Lensink, E. A. M. Bokkers, and C. G. van Reenen. 2014. Prevalence and potential influencing factors of non-nutritive oral behaviors of veal calves on commercial farms. J. Dairy Sci. 97:7021-7030.

Lidfors, L. M. 1993. Cross-sucking in group-housed dairy calves before and after weaning off milk. Appl. Anim. Behav. Sci. 38:15-24.

Manteca, X., J. J. Villalba, S. B. Atwood, L. Dziba, and F. D. Provenza. 2008. Is dietary choice important to animal welfare? J. Vet. Behav.-Clin. Appl. Res. 3:229-239.

Margerison, J., T. Preston, N. Berry, and C. Phillips. 2003. Cross-sucking and other oral behaviours in calves, and their relation to cow suckling and food provision. Appl. Anim. Behav. Sci. 80:277-286.

Mason, G. J. 1991. Stereotypies and suffering. Behav. Processes 25:103-115.

Mattiello, S., E. Canali, V. Ferrante, M. Caniatti, F. Gottardo, G. Gozzi, I. Andrighetto, and M. Verga. 2002. The provision of solid feeds to veal calves: II. Behavior, physiology, and abomasal damage. J. Anim. Sci. 80:367-375.

Mertens, D. R. 1997. Creating a system for meeting the fiber requirements of dairy cows. J. Dairy Sci. 80:1463-1481.

Miller-Cushon, E. K., R. Bergeron, K. E. Leslie, G. J. Mason, and T. J. DeVries. 2013a. Effect of early exposure to different feed presentations on feed sorting of dairy calves. J. Dairy Sci. 96:4624-4633.

Miller-Cushon, E. K., R. Bergeron, K. E. Leslie, G. J. Mason, and T. J. DeVries. 2013b. Effect of feed presentation on feeding patterns of dairy calves. J. Dairy Sci. 96:7260-7268.

Morisse, J. P., J. P. Cotte, D. Huonnic, and A. Martrenchar. 1999. Influence of dry feed supplements on different parameters of welfare in veal calves. Anim. Welf. 8:43-52.

NRC. 2000. Nutrient Requirements of Beef Cattle. 7th rev. ed. Natl. Acad. Press, Washington, DC.

Provenza, F. D., C. B. Scott, T. S. Phy, and J. J. Lynch. 1996. Preference of sheep for foods varying in flavors and nutrients. J. Anim. Sci. $74: 2355-2361$

SAS Institute. 2008. SAS software. Version 9.2. SAS Inst. Inc., Cary, $\mathrm{NC}$

Schall, R. 1991. Estimation in generalized linear-models with random effects. Biometrika 78:719-727. 
Seo, T., S. Sato, K. Kosaka, N. Sakamoto, K. Tokumoto, and K. Katoh. 1998. Development of tongue-playing in artificially reared calves: Effects of offering a dummy-teat, feeding of short cut hay and housing system. Appl. Anim. Behav. Sci. 56:1-12.

Smits, A. C., and J. G. de Wilt. 1991. Group housing of veal calves. Pages 61-66 in New Trends in Veal Calf Production. Proc. Int. Symp. Veal Calf Prod. EAAP Publication No. 52. Eur. Fed. Anim. Sci. (EAAP), Roma, Italy.

Stewart, C. L., L. A. Boyle, and N. E. O'Connell. 2011. The effect of increasing dietary fibre and the provision of straw racks on the welfare of sows housed in small static groups. Anim. Welf. 20:633-640.

Suárez, B. J., C. G. van Reenen, N. Stockhofe, J. Dijkstra, and W. J. J. Gerrits. 2007. Effect of roughage source and roughage to concentrate ratio on animal performance and rumen development in veal calves. J. Dairy Sci. 90:2390-2403.

Toofanian, F. 1976. Hairballs in veal calves. Vet. Rec. 99:444.

van Weeren-Keverling Buisman, A., E. Noordhuizen-Stassen, H. Breukink, T. Wensing, and J. Mouwen. 1988. Villus atrophy in ruminal drinking calves and mucosal restoration after reconditioning. Vet. Q. 10:164-171.

Veissier, I., A. R. Ramirez de la Fe, and P. Pradel. 1998. Nonnutritive oral activities and stress responses of veal calves in relation to feeding and housing conditions. Appl. Anim. Behav. Sci. 57:35-49.

Webb, L. E. 2014. Food for rumination-Developing novel feeding strategies to improve the welfare of veal calves. PhD Thesis. Wageningen Univ., Wageningen, the Netherlands.

Webb, L. E., E. A. M. Bokkers, B. Engel, H. Berends, W. J. J. Gerrits, and C. G. van Reenen. 2012. Behaviour and welfare of veal calves fed different amounts of solid feed supplemented to a milk replacer ration adjusted for similar growth. Appl. Anim. Behav. Sci. 136:108-116.

Webb, L. E., E. A. M. Bokkers, L. F. M. Heutinck, B. Engel, W. G. Buist, T. B. Rodenburg, N. Stockhofe-Zurwieden, and C. G. van Reenen. 2013. The effect of roughage type, amount and particle size on veal calf behavior and gastrointestinal health. J. Dairy Sci. 96:7765-7776.

Webb, L. E., B. Engel, H. Berends, C. G. van Reenen, W. J. J. Gerrits, I. J. M. de Boer, and E. A. M. Bokkers. 2014. What do calves choose to eat and how do preferences affect behaviour? Appl. Anim. Behav. Sci. 161:7-19.

Westerath, H. S., S. Laister, C. Winckler, and U. Knierim. 2009. Exploration as an indicator of good welfare in beef bulls: An attempt to develop a test for on-farm assessment. Appl. Anim. Behav. Sci. 116:126-133.

Wiepkema, P. R. 1987. Developmental aspects of motivated behavior in domestic animals. J. Anim. Sci. 65:1220-1227.

Wise, G. H., and G. W. Anderson. 1939. Factors affecting the passage of liquids into the rumen of the dairy calf. I. Methods of administering liquids: Drinking from open pail versus sucking through a rubber nipple. J. Dairy Sci. 22:697-705.

Wolfinger, R., and M. O' Connell. 1993. Generalized linear mixed models: A pseudo-likelihood approach. J. Stat. Comput. Simul. 48:233-243.

Wood-Gush, D., K. Hunt, K. Carson, and S. Dennison. 1984. The early behaviour of suckler calves in the field. Biol. Behav. 9:295-306.

Zwicker, B., L. Gygax, B. Wechsler, and R. Weber. 2012. Influence of the accessibility of straw in racks on exploratory behaviour in finishing pigs. Livest. Sci. 148:67-73. 